\title{
Compressive Strength of Composite Resins at Different Exposure Time Using LED and Halogen Units
}

\author{
Hasham Aleem ${ }^{1}$ \\ BDS \\ Faiza Ameen ${ }^{2}$ \\ BDS, MDS \\ Abdur Rehman ${ }^{3}$ \\ BDS, MDS
}

OBJECTIVE: To evaluate the compressive strength of resin composites cured with a QTH lamp \& LED unit at different exposure time.

STUDY DESIGN: In Vitro Experimental study

METHODOLOGY: Two composite materials were used in this study. Filtek Z250, (3M ESPE Dental products) and Filtek P60 (3M ESPE Dental products). For each composite 114 disc shaped samples were prepared (5mm in diameter and $2 \mathrm{~mm}$ in thickness) by using stainless steel mold. The mold was packed with the bulk of resin composite by incremental technique. Each sample was cured through the polyester strip with either QTH unit or LED unit depending on samples grouping. Samples were irradiated for 20,30 and 40 seconds. Nineteen specimens were prepared for each experimental group. Specimens were placed in artificial saliva for 24 hours after curing. Compressive strength was then determined in universal Instron Testing Machine. Data was analyzed by factorial design by Three Way ANOVA and post hoc Tukeys HSD test. Units

RESULTS: Halogen light curing unit is more effective then LED unit in terms of compressive strength. Compressive strength was influenced by exposure time $(20,30$ or $40 \mathrm{~s})(\mathrm{p}<0.001)$, by curing lights (QTH or LED) ( $<<0.001)$ and by resin composite (Filtek Z250 or ZP60) $(\mathrm{p}<0.001)$.

CONCLUSIONS: The compressive strength of specimens cured with a QTH and a LED curing light was influenced by the curing unit and the chemical composition of the material. The study concluded that superiority of LEDs over halogen lamps is questionable with different composite resins.

KEY WORDS: Composite resins, compressive strength, artificial saliva.

HOW TO CITE: Aleem H, Ameen F, Rehman A. Compressive strength of composite resins at different exposure time using led and halogen units. J Pak Dent Assoc 2018;27(1):22-26.

DOI: https://doi.org/10.25301/JPDA.271.22

Received: 08 November, 2017, Accepted: 05 February, 2018

\section{INTRODUCTION}

A $\mathrm{n}$ important milestone in the history of restorative dentistry is the development of light-cured composite resins. ${ }^{1}$ Before the advent of light cure technique, composites were cured by cold curing or chemical curing which were initiated by mixing two pastes. ${ }^{2}$ Blue light was first introduced in 1970s to overcome the complications of chemical curing dental composites. ${ }^{3}$ Improved physical properties, esthetics and operator's control over the working time are the few advantages of light cured restorative materials as compared to the chemical cured materials. ${ }^{4}$ Most commonly used light polymerizable restorative materials are resin modified glass ionomers (RMGIC), compomer and composite resins.

1. Department of Science of Dental Materials. Dow University of Health Sciences

2. Associate Professor, Dept of Science and Dental Matrials. Dow University of Health Sciences

3. Assistant Professor, Dept of Science and Dental Matrials. Hamdard University

Corresponding author: "Dr. Hashim Aleem" < hasham_alim@ hotmail.com >
Polymerization sources that have been developed till today are: argon-ion lasers, plasma-arc lamps, light emitting diodes (LED) units and quartz tungsten halogen (QTH) lamps. ${ }^{5}$ In daily clinical practice halogen lights and LED units are most frequently used. ${ }^{5}$ QTH light curing unit deliver the light with the light intensity of 400-900 $\mathrm{mW} / \mathrm{cm}^{2}{ }^{6}$ Halogen lamps, despite having low cost and have broad emission spectrum which allows almost complete polymerization of resin composite materials. However, they have many disadvantages. They require filters because they have very low capability to convert electronic energy into light and most of the energy is transformed into heat. ${ }^{7}$ Because of the halogen bulb proximity and high temperature of light unit filters degrade with the passage of the time. ${ }^{8}$ Several studies have pointed out that there is a lack of maintenance of these halogen light which further restrict their use by clinicians. ${ }^{3}$ Average lifetime of Conventional halogen lamp is between 30-50 hours. ${ }^{9}$ These limitations could negatively affect the long 
term success of the restoration due to inadequate polymerization of the material..$^{10}$ In 2001 , to overcome the limitations of the quartz tungsten halogen light, the first LED curing units were introduced. ${ }^{9}$ The mechanism involved in the LED units is combination of two different doped semiconductors instead of a hot filament.11 RW Mills proposed that LED devices utilizes, Gallium Nitride blue light which produce narrow spectrum of light (400$500 \mathrm{~nm}){ }^{3}$ Polymerization of resin monomers is initiated by the Gallium Nitride blue light because of electroluminescence effect that falls closely within absorption range of camphorquinone. ${ }^{5}$ They convert most of their electronic energy into light and therefore, to produce blue light they do not require filters. ${ }^{12}$ LEDs have constant light output in spectra and power and have the lifetime of thousand of hours. ${ }^{13}$ Till now two generations of LEDs have been introduced. There were multiple LEDs in the first generation of LED curing units and had a comparatively low power output. According to author ${ }^{10}$ these units have irradiance values similar to those of conventional light sources. Whereas, a second-generation of LCUs has light emitting diodes with high-power. The second generation LEDs offer shorter curing times and perform better working operation as compared to the first generation.

Several studies have investigated the influence of LED light-curing and halogen on properties of light-cured composites. These properties are diametrical tensile strength, ${ }^{14}$ hardness, ${ }^{3,9,12,15,16}$ depth of cure,,${ }^{9,17,18}$ flexural strength, ${ }^{19}$ abrasion resistance, ${ }^{20}$ degree of conversion ${ }^{21}$ and compressive strength. ${ }^{10}$ Both of these lights are capable of curing composite resins, however, in the performance of the cured resins some differences have been observed., ${ }^{9,17}$ Moreover, adequate association has been observed between the degree of polymerization and the composite materials and its curing time. ${ }^{9,17}$

Adequate polymerization of resin composites is essential for the ultimate success of the restorations. Polymerization effectiveness determined the materials color change, dimensional stability, mechanical properties, solubility, and biocompatibility. Materials which are generally brittle and weak in tension can best be evaluated by the compressive strength. The aim of the present study is therefore to assess the compressive strength of composite resins cured by different light curing units at different time exposures.

\section{METHODOLOGY}

Two resin composites, Filtek Z250, (3M ESPE Dental products) and Filtek P60 (3M ESPE Dental products) of
A3 shade were used for this study. Table 1 showed the details of the materials. The two light curing units evaluated were the QTH lamp (682 Deepblue Technology Co LTD, $700 \mathrm{~mW} / \mathrm{cm}^{2}$ ) and the LED light (Elipar free light (3M ESPE, $400 \mathrm{~mW} / \mathrm{cm}^{2}$ ). Table 2 showed the technical details of both the curing lights. Sample preparation was carried out in Dow Dental College, Dow University of Health Sciences. Testing was carried out in Pakistan Council of Scientific Research (PCSIR). For each composite 114

Table 1: Composition of resin material tested

\begin{tabular}{|lll|}
\hline Material & Type & Composition \\
\hline Filtek Z250 (3M ESPE & Micro Hybrid, anterior and & BIS-GMA, UDMA and BIS- \\
Dental products) & posterior. & EMA., \\
& & zirconia/silica $(0.01-3.5 \mu \mathrm{m}$, \\
& $60 \mathrm{vol} \%)$ \\
\hline Filtek P60 (3M ESPE Dental & Posterior composite & TEGDMA replaced with \\
products) & & UDMA and BIS-EMA. \\
& & zirconia/silica $(0.01$ to 3.5 \\
& & microns 60 vol $\%)$ \\
\hline
\end{tabular}

Table 2: Technical details of light curing units

\begin{tabular}{|lllll|}
\hline Code & $\begin{array}{l}\text { Light curing } \\
\text { unit } \\
\text { (Manufacturer) }\end{array}$ & Type & $\begin{array}{l}\text { Wavelength } \\
\text { Range (nm) }\end{array}$ & $\begin{array}{l}\text { Intensity } \\
\mathbf{m W} / \mathbf{c m}^{\mathbf{2}}\end{array}$ \\
\hline DB & $\begin{array}{l}\text { 682 Deepblue } \\
\text { Technology Co } \\
\text { LTD }\end{array}$ & QTH & $400-515$ & 700 \\
\hline FL & $\begin{array}{l}\text { Elipar free light } \\
\text { (3M ESPE) }\end{array}$ & LED & $440-490$ & 400 \\
\hline
\end{tabular}

samples which were disc in shaped were prepared $(5 \mathrm{~mm}$ in diameter and $2 \mathrm{~mm}$ in thickness) by using stainless steel mould. ${ }^{22}$ The mould was packed with the bulk of resin composite by incremental technique. The resin composite was slightly overfilling the mould. After insertion of the last increment, the composite was covered with transparent polyester strip (20mm length and $6 \mathrm{~mm}$ breadth) and 2.0$\mathrm{mm}$-thick glass plate was gently pressed to remove the excess material. Each sample was then irradiated through the polyester strip using QTH unit (682 Deepblue Technology Co LTD, $700 \mathrm{~mW} / \mathrm{cm}^{2}$ ) or LED unit (Elipar free light (3M ESPE, $400 \mathrm{~mW} / \mathrm{cm}^{2}$ ) depending on sample group. The curing time used for of each sample was 20 , 30 and 40 seconds for both light curing units. After the curing, cellulose strip was removed; specimens were extruded from the mould. The samples were kept in artificial saliva for 48 hours at $37^{\circ} \mathrm{C}$.

For each experimental group nineteen specimens were prepared. Digital calipers (Mitutoyo Co.) was used to measure the diameter of the prepared samples. Then evaluation of the specimens for the presence of any defects and air bubbles was carried out. Faulty specimens were excluded from the study. The samples were then randomly divided into three test groups, each group having 19 specimens. 


\section{Preparation of Artificial saliva}

The specimens were immersed in $250 \mathrm{ml}$ of artificial saliva solution at $37^{\circ} \mathrm{C}$ for 24 hours. The artificial saliva solution had an electrolyte composition similar to that of human saliva. It was composed of $4.3 \mathrm{~g}$ xylitol, $5 \mathrm{mg}$ calcium chloride, $40 \mathrm{mg}$ potassium phosphate, $1 \mathrm{mg}$ potassium thiocyanate, $1 \mathrm{~g}$ sodium carboxymethylcellulose, $0.1 \mathrm{~g}$ potassium chloride, and $100 \mathrm{~g}$ distilled deionized water. After 24 hours the specimens were removed from the artificial saliva. The surfaces were rinsed with distilled water for 30 seconds and then dry the specimens. ${ }^{23}$

\section{Compressive strength Measurements}

After 48 hours of storage compressive strength of specimens were measured. Universal testing machine (Instron universal testing machine model static) at a crosshead speed of $0.5 \mathrm{~cm} / \mathrm{min}$ and load cell of load cell $5 \mathrm{KN}$ was used to measure the compressive strength.(Figure 2) Specimens were positioned on base of the testing machine vertically and exposed to compressive load until fracture. The strength was expressed in MPa. Following formula was used to calculate the compressive strength. ${ }^{2}$

$$
\text { Compressive strength }=\frac{\operatorname{Load} \mathrm{X} 10(\mathrm{~N})}{\text { Area }(\mathrm{mm} 2)}
$$

Factorial design three way analysis of variance (ANOVA) and Tukey's HSD was used for each composite to evaluate the effects of light curing unit and exposure time on compressive strength $(\alpha=0.05)$.

\section{RESULTS}

Table 3 and table 4 showed the mean values and standard deviations for both composites used in this study. The interaction between exposure time and light curing unit for both the composites were statistically significant. $(\mathrm{p}<0.001)$ Factorial design three way ANOVA showed that compressive strength was influenced by curing lights (QTH or LED) $(\mathrm{p}<0.05)$ by exposure time $(20,30$ or $40 \mathrm{~s})(\mathrm{p}<0.001)$ and by resin composite (Filtek Z250 or ZP60) ( $<<0.001)$.

Table 3: Mean and standard deviation of compressive strength of Filtek Z250 cured by halogen and led curing light unit.

\begin{tabular}{|ccccc|}
\hline Curing unit & $\begin{array}{c}\text { Exposure } \\
\text { time }\end{array}$ & $\mathbf{N}$ & $\begin{array}{c}\text { Compressive } \\
\text { strength* }\end{array}$ & P value \\
\hline Halogen light & $\begin{array}{c}20 \mathrm{sec} \\
(\text { control })\end{array}$ & 19 & $6.652 \pm 0.138)$ & $<0.0001$ \\
\cline { 2 - 4 } & $30 \mathrm{sec}$ & 19 & $11.256( \pm 0.375)$ & \\
\cline { 2 - 4 } & $40 \mathrm{sec}$ & 19 & $18.441( \pm 0.308)$ & \\
\hline LED unit & $\begin{array}{c}20 \mathrm{sec} \\
\text { (control) }\end{array}$ & 19 & $5.153( \pm 0.5134)$ & $<0.0001$ \\
\cline { 2 - 4 } & $30 \mathrm{sec}$ & 19 & $3.326( \pm 0.040)$ & \\
\cline { 2 - 4 } & $40 \mathrm{sec}$ & 19 & $2.621( \pm 0.008)$ & \\
\hline
\end{tabular}

Table 4: Mean and standard deviation of compressive strength of Filtek P60 cured by halogen and led curing light unit.

\begin{tabular}{|cllcl|}
\hline Curing unit & Exposure time & N & $\begin{array}{c}\text { Compressive } \\
\text { strength }^{*}\end{array}$ & P value \\
\hline Halogen light & $20 \mathrm{sec}(\mathrm{control})$ & 19 & $21.92 \pm 0.242$ & $<0.0001$ \\
\cline { 2 - 4 } & $30 \mathrm{sec}$ & 19 & $7.85 \pm 0.04$ & \\
\cline { 2 - 4 } & $40 \mathrm{sec}$ & 19 & $5.92 \pm 0.016$ & \\
\hline LED unit & $20 \mathrm{sec}(\mathrm{control})$ & 19 & $9.35 \pm 0.05$ & $<0.0001$ \\
\cline { 2 - 4 } & $30 \mathrm{sec}$ & 19 & $8.44 \pm 0.029$ & \\
\cline { 2 - 4 } & $40 \mathrm{sec}$ & 19 & $6.02 \pm 0.020$ & \\
\hline
\end{tabular}

\section{DISCUSSION}

This study evaluated the compressive strength of composite resins at different curing time using led and halogen units. Over the last few years LED polymerization of oral biomaterials has become a field of intensive scientific research and commercial product development. In restorative dentistry after the introduction of LED devices, researchers showed great interest in comparing their capability with halogen lamps. Material's polymerization is greatly influence by the irradiance of curing light. Though, the degree of conversion is greatly depends on the energy dose of the light curing unit. ${ }^{24}$ For the successful outcome of the restorative material, it should have the mechanical properties similar to that of tooth structure. Several of the masticatory forces are of compressive nature and therefore compressive strength is considered to play important role in the masticatory process. The compressive strength is calculated by the maximum force applied and the cross-sectional area of test specimens. ${ }^{25}$

In the present study Filtek Z250 has higher compressive strength at 40sec when cured with halogen light as compared with the specimens that were cured with led light. Similar results were found in the study conducted by Mousavinasab $\mathrm{SM}$ et al in which they demonstrated that the total irradiance of halogen light curing unit is 2.2 times greater than the irradiance of led light curing unit. ${ }^{26}$ It is therefore expected that the physical properties of composites cured with LED is inferior then the specimens cured with halogen light. However, this relationship can only be established when curing time and other parameters like spectrum of emitted light, material and tip diameter are kept constant. ${ }^{21}$ The present study showed that the compressive strength was increased further when cured at $30 \mathrm{sec}$ and $40 \mathrm{sec}$ with halogen light as compared to $20 \mathrm{sec}$ whereas when the specimens were cured with led light markedly decrease in the compressive strength was observed at 30 and $40 \mathrm{sec}$ for Filtek Z250 specimens. Similar results were obtained in a study conducted by Eduardo Batista Franco et al in which they concluded that better results were obtained with halogen light as compared to led light in term of strength of the material. ${ }^{24}$ Similar pattern were followed for the other material used in the study that is Filtek P60. However, 
when comparing the results of FiltekZ250 and Filtek P60 the compressive strength of P60 at 20 seconds was markedly increased when cured by halogen light. Critical variables for achievement of maximum curing are wavelength, light intensity, polymerization condition and exposure time. All these factors influence the mechanical properties of lightpolymerized dental materials. ${ }^{27}$ However, in a study conducted by Kumar CNV et al they found that both halogen light and led light produced similar compressive strength and no statistical difference was found among the two lights.28 The compressive strength is influenced by the output power density, used, light intensity and time. ${ }^{9}$

It was surprising that there were only minor differences in the composite's mechanical performance when polymerized with one or the other LCU although the LED LCU had less than half of the halogen LCUs irradiance. Another study explained one possibility for the efficiency of LED LCU polymerization through the convolution of the absorption spectrum of the camphorquinone photoinitiator present in composites and the emission spectra of the LED LCUs. ${ }^{14}$ The same study showed in some cases that there was no statistically significant difference in the flexural strength and moduli of different composites when polymerized with either a commercial halogen LCU with an irradiance of 755 $\mathrm{mW} \mathrm{cm} 2$ or an LED LCU with an irradiance of $350 \mathrm{~mW}$ $\mathrm{cm}^{2}{ }^{13}$

This study shows that compressive strength of the composites cured with either a halogen lamp or a LED source demonstrated different results. In summary, the impact of the light intensity, output power density of the LCUs, curing time and chemical composition of the materials, should be considered. More research is required to illuminate the mechanical properties of composites cured with LED curing units, to address the factors mentioned above.

\section{CONCLUSION}

Under the limitations of this study following conclusions can be drawn:

Filtek Z250 has higher compressive strength at 40sec when cured with halogen light whereas Filtek Z250 has lower compressive strength at 40sec when cured with LED light. At $20 \mathrm{sec}$ Filtek P60 has higher compressive strength when cured with halogen light. Filtek P60 has lower compressive strength at 40sec when cured with LED light. Compressive strength was increased further when cured at $30 \mathrm{sec}$ and $40 \mathrm{sec}$ with halogen light as compared to $20 \mathrm{sec}$. When the specimens were cured with led light markedly decrease in the compressive strength was observed at 30 and $40 \mathrm{sec}$ for Filtek Z250 specimens. Same sequence was followed for Filtek P60.

\section{CONFLICT OF INTEREST}

None declared

\section{REFERENCES}

1. Aguiar FH, Braceiro AT, Ambrosano GM, Lovadino JR. Hardness and diametral tensile strength of a hybrid composite resin polymerized with different modes and immersed in ethanol or distilled water media. Dent Mater. 2005;21:1098-03.

https://doi.org/10.1016/j.dental.2004.11.010

2. Anusavice KJ, Shen C, Rawls HR. Phillips' Science Of Dental Materials: Elsevier Health Sciences; 2012.

3. Mills R, Uhl A, Jandt K. Optical power outputs, spectra and dental composite depths of cure, obtained with blue light emitting diode (LED) and halogen light curing units (LCUs). Br Dent J. 2002;193:459-63.

https://doi.org/10.1038/sj.bdj.4801597

4. David JR, Gomes OM, Gomes JC, Loguercio AD, Reis A. Effect of exposure time on curing efficiency of polymerizing units equipped with light-emitting diodes. J Oral Sci. 2007;49:19-24.

https://doi.org/10.2334/josnusd.49.19

5. García AH, Lozano MAM, Vila JC, Escribano AB, Galve PF. Composite resins. A review of the materials and clinical indications. Med Oral Patol Oral Cir Bucal. 2006;11:215-20.

6. Rueggeberg F, Caughman W, Curtis J. Effect of light intensity and exposure duration on cure of resin composite. Oper Dent. 1994;19:26.

7. Yap A, Soh M. Curing efficacy of a new generation high-power LED lamp. Oper Dent. 2005;30:758.

8. Mills R, Jandt K, Ashworth S. Restorative Dentistry: Dental composite depth of cure with halogen and blue light emitting diode technology. Br Dent J. 1999;186:388-91. https://doi.org/10.1038/sj.bdj.4800120

9. Uhl A, Mills RW, Vowles RW, Jandt KD. Knoop hardness depth profiles and compressive strength of selected dental composites polymerized with halogen and LED light curing technologies. J Biomed Mater Res. 2002;63:729-38. https://doi.org/10.1002/jbm.10390

10. Jandt K, Mills R, Blackwell G, Ashworth S. Depth of cure and compressive strength of dental composites cured with blue light emitting diodes (LEDs). Dent Mater. 2000;16:41-47.

https://doi.org/10.1016/S0109-5641(99)00083-4

11. Vandewalle K, Roberts H, Tiba A, Charlton D. Thermal emission and curing efficiency of LED and halogen curing lights. Oper Dent. 2005;30:257-64.

12. Price RB, Felix CA, Andreou P. Knoop hardness of ten 
resin composites irradiated with high-power LED and quartztungsten-halogen lights. Biomater. 2005;26:2631-41. https://doi.org/10.1016/j.biomaterials.2004.06.050

13. Stahl F, Ashworth SH, Jandt KD, Mills RW. Lightemitting diode (LED) polymerisation of dental composites: flexural properties and polymerisation potential. Biomater. 2000;21:1379-85. https://doi.org/10.1016/S0142-9612(00)00029-6 14. Tolosa MCCG, Paulillo LAMS, Giannini M, Santos AJSd, Dias CTdS. Influence of composite restorative materials and light-curing units on diametrical tensile strength. Braz Oral Res. 2005;19:123-26. https://doi.org/10.1590/S1806-83242005000200009 15. Cefaly DFG, Ferrarezi GAdO, Tapety CMC, Lauris JRP, Navarro MFdL. Microhardness of resin-based materials polymerized with LED and halogen curing units. Braz Dent J. 2005;16:98-102. https://doi.org/10.1590/S0103-64402005000200002

16. Soh M, Yap A, Siow K. The effectiveness of cure of LED and halogen curing lights at varying cavity depths. Operative dentistry. 2002;28:707-15.

17. Koupis NS, Vercruysse CW, Marks LA, Martens LC, Verbeeck RM. Curing depth of (polyacid-modified) composite resins determined by scraping and a penetrometer. Dent Mater. 2004;20:908-14. https://doi.org/10.1016/j.dental.2004.01.001

18. Obici AC, Sinhoreti MAC, Correr Sobrinho L, Goes MFd, Consani S. Evaluation of depth of cure and Knoop hardness in a dental composite photo-activated using different methods. Braz Dent J. 2004;15:199-203.

https://doi.org/10.1590/S0103-64402004000300007

19. Miyazaki M, Hattori T, Ichiishi Y, Kondo M, Onose H, Moore B. Evaluation of curing units used in private dental offices. Oper Dent. 1997;23:50-54.

20. Martinelli J, Pires-de-Souza FdC, Casemiro LA, Tirapelli $\mathrm{C}$, Panzer $\mathrm{H}$. Abrasion resistance of composites polymerized by light-emitting diodes (LED) and halogen light-curing units. Braz Dent J. 2006;17:29-33. https://doi.org/10.1590/S0103-64402006000100007 21. Halvorson RH, Erickson RL, Davidson CL. Energy dependent polymerization of resin-based composite. Dent Mater. 2002;18:463-69.

https://doi.org/10.1016/S0109-5641(01)00069-0

22. Ceballos L, Fuentes M, Tafalla Pastor H, Martínez Á, Flores J, Rodríguez J. Curing effectiveness of resin composites at different exposure times using LED and halogen units. J Clin Exp Dent. 2009;1:8-13.

23. Jeong S-S, Chung K-H. Comparative remineralization effects of human and artificial saliva compositions on incipient dental caries. J Korean Acad Oral Health. 2017;41:50-55.

https://doi.org/10.11149/jkaoh.2017.41.1.50

24. Franco EB, Santos PAd, Mondelli RFL. The effect of different light-curing units on tensile strength and microhardness of a composite resin. J App Oral Sci. 2007;15:470-74.

\section{https://doi.org/10.1590/S1678-77572007000600003}

25. Silva CM, Dias KRHC. Compressive strength of esthetic restorative materials polymerized with quartz-tungstenhalogen light and blue LED. Braz Dent J. 2009;20:54-57. https://doi.org/10.1590/S0103-64402009000100009

26. Mousavinasab SM, Meyers I. Comparison of depth of cure, hardness and heat generation of LED and high intensity QTH light sources. Eur J Dent. 2011;5:299.

27. Cavalcante L, Peris A, Amaral C, Ambrosano G, Pimenta L. Influence of polymerization technique on microleakage and microhardness of resin composite restorations. Oper Dent. 2003;28:200-06.

28. Kumar C, Gururaj M, Paul J, Krishnaprasada L, Divyashree R. A comparative evaluation of curing depth and compressive strength of dental composite cured with halogen light curing unit and blue light emitting diode: an in vitro study. J Contemp Dent Pract. 2012;13:834-37. 